\title{
Inflammatory Markers: Exhaled Nitric Oxide and Carbon Monoxide During the Ovarian Cycle
}

\author{
Adam Antczak, ${ }^{1}$ Maciej Ciebiada, ${ }^{1,3}$ Sergei A. Kharitonov, ${ }^{2}$ Pawel Gorski, ${ }^{1}$ \\ and Peter J. Barnes ${ }^{2}$
}

\begin{abstract}
Nitric oxide (NO) production and carbon monoxide (CO) production are increased in inflammatory lung diseases. Although there are some pieces of evidence for hormonal modulation by estrogen, little is known about exhaled $\mathrm{NO}$ and $\mathrm{CO}$ during the ovarian cycle. In 23 subjects, we measured exhaled NO and CO by an online analyzer. Significantly higher levels of exhaled NO were found at the midcycle compared with those in the premenstrual period or during menstruation. Higher levels of $\mathrm{CO}$ were after ovulation and reached a peak in the premenstrual phase. The lowest levels of $\mathrm{CO}$ were observed in the first days of the estrogen phase. In males, there was no significant variation in exhaled $\mathrm{NO}$ and $\mathrm{CO}$. Exhaled $\mathrm{NO}$ and $\mathrm{CO}$ levels vary during the ovarian cycle in women, and this fact should be taken into account during serial measurements of these markers in the female population.
\end{abstract}

KEY WORDS: nitric oxide; carbon monoxide; lung diseases; asthma; inflammation.

\section{INTRODUCTION}

Nitric oxide (NO) and carbon monoxide (CO) may be produced in increased amounts in various inflammatory lung diseases $[1,2]$. Exhaled nitric oxide is increased in bronchial asthma [3], during upper respiratory tract viral infections [4], bronchiectasis [5], and active fibrosing alveolitis [6]. Exhaled $\mathrm{CO}$ is increased in asthma [7], cystic fibrosis [8], bronchiectasis [9], and respiratory tract infections in normal subjects [10]. In cystic fibrosis, NO is lower compared in healthy subjects possibly due to a reduced expression of inducible NO synthase in the airways [11].

Both exhaled $\mathrm{NO}$ and $\mathrm{CO}$ are recognized as markers of inflammation and tend to decrease during steroid treatment, making this measurement of potential value in monitoring lung inflammation [12].

\footnotetext{
${ }^{1}$ Department of Pneumology and Allergy, Medical University of Lodz, Kopcińskiego 22, 90-153 Łódź, Poland

${ }^{2}$ Department of Thoracic Medicine, National Heart and Lung Institute, Imperial College, London, UK

${ }^{3}$ To whom correspondence should be addressed at Department of Pneumology and Allergy, Medical University of Lodz, Kopcińskiego 22, 90-153 Łódź, Poland. E-mail: maciej_ciebiada@op.pl
}

Although little is known about the regulation of airway $\mathrm{NO}$ and $\mathrm{CO}$ production, indirect evidence suggests that it may be modulated by estrogen related to the ovarian cycle in women. It has been noted that asthma symptoms are less severe in midcycle when estrogen to progesterone ratio in systemic blood is highest. They worsen during menses when the ratio goes down after ovulation [13]. Kharitonov et al. have demonstrated that NO production is influenced by cyclical hormonal changes in women. There was an increase of more than $100 \%$ of peak NO at midcycle [14]. Estrogen increases the expression of endothelial NO synthase in a human bronchial epithelial cell line through a process that involves the stimulation of estrogen receptors and calcium influx [15].

Little is known about exhaled CO during the ovarian cycle. Endogenous production of carbon monoxide is increased during the progesterone phase of the ovarian cycle. This is correlated with an increased in red cell catabolism and an increased in reticulocyte counts [16]. An increased $\mathrm{CO}$ in subjects on contraceptive drugs may also be related to the activity of progesterone [17]. This increase in $\mathrm{CO}$ may be related to heme oxygenase 1 (HO-1) activation by several stimulants 
including hormones [17, 18]. Progesterone has been shown to increase expression of HO-1 in myometrial cells [19]. Also, endogenously generated NO induces the expression of HO-1 in vascular endothelial and smooth muscle cells [20]. This may provide protection against oxidative stress to endothelium [21]. On the other hand, $\mathrm{CO}$ can bind to the heme moiety of NOS and thus inhibit NO production [22].

Since both $\mathrm{NO}$ and $\mathrm{CO}$ are increasingly used as simple and noninvasive tools for monitoring airway inflammation, standardization is important especially when repeated measurements of exhaled $\mathrm{NO}$ and $\mathrm{CO}$ are made in female subjects. For this reason, we undertook a study of serial measurements of exhaled $\mathrm{NO}$ and $\mathrm{CO}$ during ovarian cycle.

\section{METHODS}

\section{Subjects}

We included 15 healthy, nonsmoking, regularly menstruating females, who were not taking any medications (including oral contraception; mean age, 34 9 years). Eight healthy, nonsmoking age-matched males (mean age, $34 \pm 3$ years) comprised the control group. All the subjects were recruited from staff members at the Royal Brompton Hospital. A series of measurements were performed on them at frequent intervals (days 1-6, $7-12,13-19,20-25$, and 26-31; day 1 was the 1 st day of menstruation) during their ovarian cycle. Male subjects also underwent similar serial measurements. All subjects were asked to inhale room air at total lung capacity and then to exhale slowly into a tube connected directly to the $\mathrm{NO}$ and $\mathrm{CO}$ analyzer. All subjects signed a consent form, and the study was approved by the local Ethics Committee.

\section{Exhaled NO measurements}

Exhaled NO was measured by a chemiluminescence analyzer (model LR2000; Logan Research, Rochester, UK) sensitive to NO from 1 to $5,000 \mathrm{ppb}$ (by volume) and with a resolution of $0.3 \mathrm{ppb}$ which was designed for online recording of exhaled $\mathrm{NO}$, as previously described [23]. The analyzer was calibrated using certified NO mixtures (90 and $436 \mathrm{ppb}$ ) in nitrogen (BOC Special Gases, Guilford, UK). Measurement of exhaled NO was made by slow exhalation (5$6 \mathrm{l} / \mathrm{min}$ ) from total lung capacity for $20-30 \mathrm{~s}$ against a resistance of $3 \pm 0.4 \mathrm{mmHg}$. Two successive recordings were taken, and plateau values were used in all calculations.

\section{Exhaled CO measurement}

Exhaled $\mathrm{CO}$ was measured using a chemiluminescence analyzer (model LR2000; Logan Research, Rochester, UK) sensitive to $1-500 \mathrm{ppm}$ (by volume) $\mathrm{CO}$ adapted for online recording. The subjects exhaled slowly at total lung capacity with a constant flow $(5-6 \mathrm{l} / \mathrm{min})$ against a resistance of $3 \pm$ $0.4 \mathrm{mmHg}$ over 20-30 s [24]. Two successive recordings were made, and maximal values were used in all calculations. Ambient $\mathrm{CO}$ levels were recorded before each measurement and subtracted from measured values.

\section{Statistical analysis}

Data are expressed as means \pm standard deviation. Differences between exhaled $\mathrm{NO}$ and $\mathrm{CO}$ levels produced during particular phases of ovarian cycle were compared with Kruskal-Wallis test.

\section{RESULTS}

Table 1 shows mean exhaled NO and CO levels from men and women. Measurements were performed during the first visit. There were no significant differences in either $\mathrm{NO}$ or $\mathrm{CO}$ levels between men and women; however, the variability was greater in women.

There were no significant differences between repeated measurements in men (Table 2).

Exhaled NO changes in expired NO levels during ovarian cycle are shown in Fig. 1. Significantly greater levels of exhaled NO were observed in the midcycle compared with those in the first third of progestational phase and premenstrual period $(6.8 \pm 2.17$ versus $4.1 \pm$ 1.18 and $4.3 \pm 1.6 \mathrm{ppb} ; p<0.001$ and $p<0.01$, respectively) and during menstruation $(5.0 \pm 2.11 \mathrm{ppb} ; p<0.02)$.

Exhaled CO changes in exhaled CO levels in relation to ovarian cycle are shown in Fig. 2. In contrast to changes in exhaled NO levels, exhaled CO levels

Table 1. Exhaled Nitric Oxide (NO) and Carbon Monoxide (CO) Levels in Sex Groups

\begin{tabular}{lccr}
\hline & Male $(n=8)$ & Female $(n=15)$ & $p$ value \\
\hline Age (year) & $34 \pm 3$ & $34 \pm 9$ & $>0.05$ \\
NO (ppb) & $5.08 \pm 1.23$ & $5.36 \pm 3.6$ & $>0.05$ \\
CO (ppm) & $3.02 \pm 0.96$ & $3.39 \pm 2.87$ & $>0.05$ \\
\hline
\end{tabular}

Means \pm standard deviations are shown 
Table 2. Exhaled Nitric Oxide (NO) and Carbon Monoxide (CO) in Repeated Measurements in Men

\begin{tabular}{lcccrr}
\hline & Days 1-6 & Days 7-12 & Days 13-19 & Days 20-25 & Days 26-31 \\
\hline NO (ppb) & $5.08 \pm 1.23$ & $5.19 \pm 1.6$ & $5.34 \pm 1.2$ & $5.12 \pm 1.9$ & $4.9 \pm 2.0$ \\
CO (ppm) & $3.02 \pm 0.96$ & $3.3 \pm 1.15$ & $2.99 \pm 1.9$ & $3.4 \pm 2.6$ & $3.15 \pm 1.7$ \\
\hline
\end{tabular}

No variability either in NO nor CO levels was observed. Mean values \pm standard deviations are shown

were not the highest in the midcycle $(3.9 \pm 1.67 \mathrm{ppm})$. Higher levels of exhaled CO were observed during the first third of progestational phase of the endometrial cycle (after ovulation) and reached peak values in premenstrual phase $(4.4 \pm 1.9$ and $5.9 \pm 3.28$ ppm, respectively), both significantly higher than values obtained from measurements done in other phases of the ovarian cycle $(p<0.05)$. These were followed by a decreased in $\mathrm{CO}$ levels during menstruation with a significant fall in the first days of the estrogen phase $(3.6 \pm 2.87$ and $3.1 \pm$ 1.0 ppm, respectively).

No correlations between exhaled NO and CO levels during ovarian cycle were found.

\section{DISCUSSION}

In this study, we have shown that exhaled NO (ENO) and CO (ECO) levels vary during the ovarian cycle. NO levels are highest in the midcycle and exhaled $\mathrm{CO}$ is increased during premenstrual phase. Hormonemediated effects on basal metabolic rate and airway cell production of NO and systemic and airway production of CO may underlie changes in exhaled NO and CO.

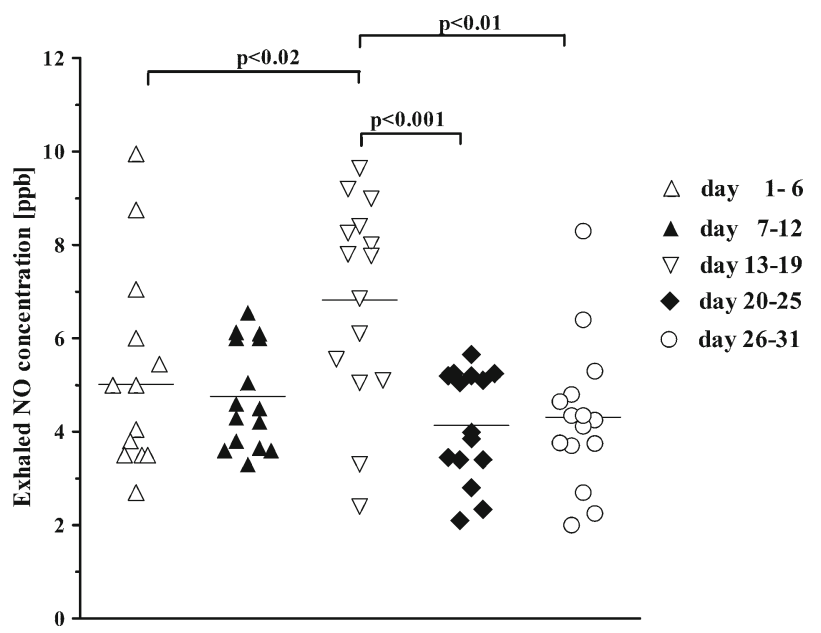

Fig. 1. Changes of exhaled nitric oxide $(N O)$ levels in expired air in relation to ovarian cycle. Day 1 is the 1st day of menstruation. Mean values are shown as horizontal bars.
Endogenous NO is continuously generated from Larginine, through the action of the nitric oxide synthases including constitutively expressed neuronal and endothelial types and inducible one. The latter isoform has the greatest activity and can be induced by inflammatory cytokines, endotoxines, and viral infections. NO found in the exhaled air (ENO) reflects mainly enzymatic NO production in the respiratory tract but, in a much lesser degree, may be a result of generation of this mediator through a NOS-independent pathway (from $S$-nitrosothiols) [25]. Nitric oxide, found in the exhaled air, may originate from the sinuses, stomach, and lower respiratory tract. Contamination with air from the sinuses could be prevented during the measurement by exhalation against a resistance placed in the mouth, which raises the soft palate and closes the communication to the rhinopharynx. Gastric NO, even very high, in healthy subjects does not contaminate exhaled NO, as the upper and lower esophageal sphincters are closed [26]. Alteration of ENO by smoking, caffeine, nitrate, or nitrate-containing foods ingestion [27] should be pre-

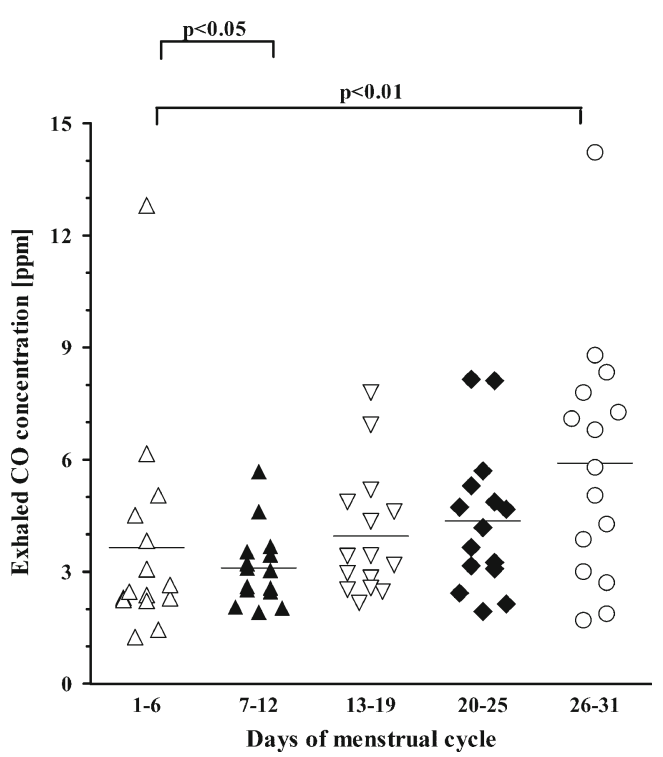

Fig. 2. Changes of exhaled carbon monoxide $(C O)$ levels in relation to ovarian cycle. Day 1 is the 1 st day of menstruation. Mean values are shown as horizontal bars. 
vented by abstaining from smoking and eating before the test (according to the ATS criteria) [28]. In such conditions, ENO concentration results mainly from the NO production and its release from the respiratory tract to the airway lumen and depends on the airflow rate from the distal part of respiratory tract to the mouth [29]. Both may be affected by hormones during the ovarian cycle. Kirsch et al. [15] have shown that functional estrogen receptors are expressed in human airway epithelial cells and endothelial NO synthase activity more than doubled at $5 \mathrm{~min}$ after exposure to physiological concentrations of estrogen [15]. It could be reflected by higher ENO concentrations in midcycle (preovulation and ovulation phases) where the estrogen concentration in the blood is the highest. Furthermore, progesterone increases resting minute ventilation during the luteal phase by central neural mechanisms [30] and augments ventilatory responses to hypoxemia and hypercapnia via an increased sensitivity of chemoreceptors [3032]. Increased respiratory rate may result in the fall of FeNO [33], indicated in the luteal phase of our study. This may have some functional relevance. Asthma morbidity may be affected by the ovarian cycle. A study by Eliasson et al. showed that $33 \%$ of asthmatic women had significant worsening of total pulmonary symptom scores during either the premenstrual period, the menstrual period, or both with maximum increase in dyspnea, wheezing, and chest tightness during the premenstrual period [13]. Fewer symptoms were reported at midcycle when estrogen levels are highest. Moreover, estrogen treatment can be a steroidsparing therapy in women with refractory asthma [34]. We observed the lowest levels of exhaled NO in the progestational phase when asthma symptoms usually worsen compared with those present in the midcycle. This could reflect a protective effect of $\mathrm{NO}$ derived from constitutive NO synthase in the airways of asthmatic patients.

In contrast to ENO, ECO reflects mainly systemic production of $\mathrm{CO}$ and is closely related to $\mathrm{COHgb}$ levels in the blood. ECO arises from the endogenous enzymatic degradation of hemoglobin ( $85 \%$ ) catalyzed by heme oxygenase and degradation of myoglobin, catalase, and cytochromes (15\%) [35]. Although the alveoli are the main place for $\mathrm{CO}$ elimination, ECO can be contaminated by carbon monoxide from the sinuses [35]. Through induction of HO-1, endogenous $\mathrm{CO}$ production could be increased by hypoxia, heavy metals, heme, exogenous $\mathrm{CO}$, proinflammatory cytokines, hyperglycemia and hormones [36], and endogenously generated NO [20]. Thus, ECO may serve as a marker in diabetes [37], cirrhosis [38] hemoglobinopathies [39] asthma [7], cystic fibrosis [8], bronchiectasis [9], and respiratory tract infections [10]. In our study, exhaled $\mathrm{CO}$ levels were high in the secretory phase, reaching their highest levels in the premenstrual phase. Although a causative role in the increased blood and hemoglobin loss has been suggested to be the main source of increased $\mathrm{CO}$ production, there is no clear indication as to the mechanism by which exhaled $\mathrm{CO}$ concentration is highest in the premenstrual phase, as there is no increased hemoglobin degradation at this time. However, progesterone may significantly induce the expression of HO-1 and HO-2 mRNAs and HO-1 protein synthesis with subsequent $\mathrm{CO}$ production in human myometrium [19]. This has been proposed as an endogenous inhibitory mechanism of myometrial contractility during pregnancy. Since HO-1 is expressed in airway epithelial cells and macrophages, it is plausible that increased concentrations of exhaled $\mathrm{CO}$ in the luteal phase are also a result of HO-1 induction by progesterone.

Furthermore, in our study the lowest exhaled NO concentrations are associated with the highest $\mathrm{CO}$ levels. Although there are no inverse correlations between both gases, the lowest $\mathrm{NO}$ levels and the highest $\mathrm{CO}$ are observed in the progestational phase of ovarian cycle. $\mathrm{CO}$ can bind to the heme moiety of NOS and thus inhibit NO production [40]. On the other hand, growing evidence suggests that $\mathrm{NO}$ donors and $\mathrm{NO}$ itself induces expression of HO-1 in smooth muscle cell lines [40]. This is of a great importance in the sustained production of $\mathrm{NO}$ in oxidative stress providing an endogenous defense mechanism against reactive nitrogen species [41]. These two phenomena could reflect a physiologic pattern of exhaled NO and $\mathrm{CO}$ production. $\mathrm{CO}$ could be an inhibitor of airway inducible NO synthase, and this is why the lowest NO levels are observed when $\mathrm{CO}$ reaches its highest concentrations. On the other hand, the lowest $\mathrm{CO}$ levels should be associated with the highest of those exhaled NO, but this was not observed in our study. The lowest levels of exhaled $\mathrm{CO}$ were observed in the first days of follicular phase when NO is far from its highest values. This could indicate that the regulatory network for $\mathrm{NO}$ and $\mathrm{CO}$ production in the airways is likely to be more complex.

\section{CONCLUSIONS}

Both exhaled NO and $\mathrm{CO}$ are increasingly used as noninvasive indices of airway inflammation and may be useful in monitoring airway diseases. It is important to take into account the effect of the ovarian cycle on these measurements. Repeated measurements of exhaled NO 
and $\mathrm{CO}$ in women should be performed at the same time as the ovarian cycle.

Declaration of Interest. The authors report no declarations of interest.

Open Access. This article is distributed under the terms of the Creative Commons Attribution Noncommercial License which permits any noncommercial use, distribution, and reproduction in any medium, provided the original author(s) and source are credited.

\section{REFERENCES}

1. Ignarro, L.J. 1990. Biosynthesis and metabolism of endotheliumderived nitric oxide. Annual Review of Pharmacology Toxicology 30: 535-560.

2. Choi, A.M., and J. Alam. 1996. Heme-oxygenase-1: Function, regulation, and implication of novel stress-inducible protein in oxidant-induced lung injury. American Journal of Respiratory Cell and Molecular Biology 15: 9-19.

3. Michils, A., S. Baldassarre, and A. Van Muylem. 2008. Exhaled nitric oxide and asthma control: A longitudinal study in unselected patients. The European Respiratory Journal 31: 539-546.

4. Scadding, G. 2007. Nitric oxcide in the airways. Current Opinion in Otolaryngology \& Head and Neck Surgery 15: 258-263.

5. Shoemark, A., and R. Wilson. 2009. Bronchial and peripheral airway nitric oxide in primary ciliary dyskinesia and bronchiectasis. Respiratory Medicine 103: 700-706.

6. Paredi, P., S.A. Kharitonov, S. Loukides, P. Pantelidis, R.M. du Bois, and P.J. Barnes. 1999. Exhaled nitric oxide is increased in active fibrosing alveolitis. Chest 115: 1352-1356.

7. Ohara, Y., T. Ohrui, T. Morikawa, M. He, H. Yasuda, M. Yamaya, and H. Sasaki. 2006. Exhaled carbon monoxide levels in school-age children with episodic asthma. Pediatric Pulmonology 41: 470-474.

8. Paredi, P., P.L. Shah, P. Montuschi, P. Sullivan, M.E. Hodson, S. A. Kharitonov, and P.J. Barnes. 1999. Increased carbon monoxide in exhaled air of patients with cystic fibrosis. Thorax 54: 917-920.

9. Horvath, I., S. Loukides, T. Wodehouse, S.A. Kharitonov, P.J. Cole, and P.J. Barnes. 1998. Increased levels of exhaled carbon monoxide in bronchiectasis: A new marker of oxidative stress. Thorax 53: 867-870.

10. Andersson, J.A., R. Uddman, and L.O. Cardell. 2002. Increased carbon monoxide levels in the nasal airways of subjects with a history of seasonal allergic rhinitis and in patients with upper respiratory tract infection. Clinical and Experimental Allergy 32: 224-227.

11. Meng, Q.H., D.R. Springall, and A.E. Bisschop. 1998. Lack of inducible nitric oxide synthase in bronchial epithelium: a possible mechanism of susceptibility to infection in cystic fibrosis. The Journal of Pathology 184: 323-331.

12. Kharitonov, S.A., D. Yates, and P.J. Barnes. 1996. Inhaled glucocorticosteroids decrease nitric oxide in exhaled air of asthmatic patients. American Journal of Respiratory and Critical Care Medicine 153: 454-457.

13. Eliasson, O., H.H. Scherzer, and A.C. DeGraff. 1986. Morbidity in asthma in relation to the menstrual cycle. The Journal of Allergy and Clinical Immunology 77: 87-94.

14. Kharitonov, S.A., R.B. Logan-Sinclair, C.M. Busset, and E.A. Shinebourne. 1994. Peak expiratory nitric oxide differences in men and women: relation to the menstrual cycle. British Heart Journal 72: 243-245.

15. Kirsch, E.A., I.S. Yuhanna, Z. Chen, Z. German, T.S. Sherman, and P.W. Shaul. 1998. Estrogen acutely stimulates nitric oxide synthase in H441 human airway epithelial cells. American Journal of Respiratory Cell and Molecular Biology 20: 658666.

16. Mercke, C., E. Cavallin-Stahl, and B. Lundh. 1975. Carbon monoxide production and reticulocyte count in normal women. Effect of contraceptive drugs and smoking. Acta Medica Scandinavica 198: $155-160$.

17. Applegate, L.A., P. Luscher, and R.M. Tyrell. 1991. Induction of heme-oxygenase: A general response to oxidant stress in cultured mammalian cells. Cancer Research 51: 974-978.

18. Kim, Y.M., H.A. Bergonia, C. Muller, B.R. Pitt, W.D. Watkins, and J.R.J. Lancaster. 1995. Loss and degradation of enzyme-bond heme induced by cellular nitric oxide synthesis. Biological Chemistry 270: 5710-5713.

19. Acevedo, C.H., and A. Ahmed. 1998. Hemoxygenase-1 inhibits human myometrial contractility via carbon monoxide and is upregulated by progesterone during pregnancy. Journal of Clinical Investigation 101: 949-955.

20. Hartslfield, C.L., J. Alam, J.L. Cook, and A.M. Choi. 1997. Regulation of heme oxygenase-1 gene expression in vascular smooth muscle cells by nitric oxide. The American Journal of Physiology 273: 980-988.

21. Motterlini, R., R. Foresti, M. Intaglietta, and R.M. Winslow. 1996. NO-mediated activation of heme-oxygenase: Endogenous cytoprotection against oxidative stress to endothelium. The American Journal of Physiology 270: 107-114.

22. Maines, M.D. 1997. The heme oxygenase system: a regulator of second messenger gases. Annual Review of Pharmacology and Toxicology 37: 517-554.

23. Kharitonov, S.A., K.F. Chung, D. Evans, B.J. O'Connor, and P.J. Barnes. 1996. Increased exhaled nitric oxide in asthma is mainly derived from lower respiratory tract. American Journal of Respiratory and Critical Care Medicine 153: 1773-1780.

24. Horvath, I., L.E. Donnelly, A. Kiss, P. Paredi, S.A. Kharitonov, and P.J. Barnes. 1998. Raised levels of exhaled carbon monoxide are associated with increased expression of heme oxygenase- 1 in airway macrophages in asthma: A novel marker of oxidative stress. Thorax 53: 668-672.

25. Hunt, J.F., K. Fang, R. Malik, A. Snyder, N. Malhorta, and T.A.E. Platts-Mills. 2000. Endogenous airway acidification: Implications for asthma pathophysiology. American Journal of Respiratory and Critical Care Medicine 161: 694-699.

26. Lundberg, J.O., E. Weitzberg, J.M. Lundberg, and K. Alving. 1994. Intragastric nitric oxide production in humans: Measurements in expelled air. Gut 35: 1543-1546.

27. Olin, A.C., A. Aldenbratt, A. Ekman, G. Ljungkvist, L. Jungersten, K. Alving, and K. Toren. 2001. Increased nitric oxide in exhaled air after intake of a nitrate-rich meal. Respiratory Medicine 95: $153-158$.

28. American Thoracic Society, European Respiratory Society. 2005. ATS/ERS recommendations for standardized procedures for the online and offline measurement of exhaled lower respiratory nitric oxide and nasal nitric oxide, 2005. American Journal of Respiratory and Critical Care Medicine 171: 912-930. 
29. Prieto, L. 2002. Measurement of exhaled nitric oxide concentrations in asthma. Technical aspects and clinical usefulness. Alergología e Inmunología Clínica 17: 72-87.

30. Bayliss, D.A., and D.E. Millhorn. 1992. Central neural mechanisms of progesterone action: Application to the respiratory system. Journal of Applied Physiology 73: 393-404.

31. Oosthuyse, T., and A.N. Bosch. 2006. Influence of menstrual phase on ventilatory responses to submaximal exercise. SAJSM 18: 31-37.

32. Dutton, K., B.A. Blankskby, and A.R. Morton. 1989. CO, sensitivity changes during the menstrual cycle. Journal of Applied Physiology 67: 517-522.

33. West, E., M. Skowronski, A. Coreno, and E.R. McFadden. 2005. The effects of hyperpnea on exhaled nitric oxide synthesis in normal subjects. Chest 128: 3316-3321.

34. Myers, J.R., and C.B. Sherman. 1994. Should supplemental estrogens be used as steroid-sparing agents in asthmatic women? Chest 106: 318-319.

35. Kharitonov, S.A., and P.J. Barnes. 2002. Biomarkers of some pulmonary diseases in exhaled breath. Biomarkers 7: 1-32.

36. Ryter, S.W., J. Alam, and A.M. Choi. 2006. Heme oxygenase-1 carbon monoxide: From basic science to therapeutic applications. Physiological Reviews 86: 583-650.
37. Paredi, P., W. Biernacki, G. Invernizzi, S.A. Kharitonov, and P. J. Barnes. 1999. Exhaled carbon monoxide levels elevated in diabetes and correlated with glucose concentration in blood: A new test for monitoring the disease? Chest 116: 10071011.

38. De las Heras, J., J. Fernández, P. Ginès, A. Cárdenas, R. Ortega, and M. Navasa. 2003. Increased carbon monoxide production in patients with cirrhosis with and without spontaneous bacterial peritonitis. Hepatology 38: 452-459.

39. James, E.B., H.J. Vreman, R.J. Wong, D.K. Stevenson, E. Vichinsky, L. Schumacher, and J.Y. Hall. 2010. Elevated exhaled carbon monoxide concentration in hemoglobinopathies and its relation to red blood cell transfusion therapy. Pediatric Hematology and Oncology 27: 112-121.

40. Morita, T., and S. Kourembanas. 1995. Endothelial cell expression of vasoconstrictors and growth factors is regulated by smooth muscle cell-derived carbon monoxide. Journal of Clinical Investigation 96: 2676-2682.

41. Yet, S.F., A. Pellacani, C. Patterson, L. Tan, S.C. Folta, W.S. Lee, C.M. Hsieh, and M.A. Parella. 1997. Induction of heme-oxygenase-1 expression in vascular smooth muscle cells. A link to endotoxic shock. The Journal of Biological Chemistry 272: 4295-4301. 